\title{
Uyuni, capital turística de Bolivia Aproximaciones antropológicas a un fenómeno visual posmoderno desbordante*
}

\author{
Damir Galaz-Mandakovic Fernández** \\ Universidad Católica del Norte
}

\section{Resumen}

Se analiza el turismo como nueva agencia económica de una ciudad que se reconvierte después de una crisis. En este proceso los relatos y las actitudes posmodernas de los turistas -centrados en una visualidad y exotización con base en cierta razón artesanal- ayudan a comprender desde enfoques eurocéntricos y esencialistas los procesos culturales de la zona de Uyuni y sus áreas contiguas. Como estrategia local de desarrollo, el turismo ha contribuido a construir una etnicidad estática, y a la martirización y glorificación de la historia en cuanto relato elaborado a partir de los moldeamientos que induce el turismo.

Palabras clave

Uyuni, turismo, posmodernidad, etnicidad.

Recibido: 22/10/2013 - Aceptado: 11/04/2014

* Este trabajo forma parte de la investigación para elaborar mi tesis de doctorado en Antropología Social en la Universidad Católica del Norte y Universidad de Tarapacá.

**Correo electrónico: damirgalaz@gmail.com 


\title{
Uyuni, Bolivia's touristic capital. Anthropological approaches to a postmodern visual phenomenon
}

\author{
Damir Galaz-Mandakovic Fernández** \\ Universidad Católica del Norte
}

\begin{abstract}
Tourism is analyzed as a new economic agent in a city that is reconverted after a crisis. In this process, narratives and post-modern attitudes of tourists - centered on visuality and an exoticized craft-like idea- make it possible to understand the cultural processes in Uyuni and surrounding areas from an Eurocentric and essentialist point of view.

As a strategy for local development, tourism has contributed in the construction of a static ethnicity and to a state of martyrdom and glorification of history as a narrative developed on the base of models induced by tourism.
\end{abstract}

\section{KEY WORDS}

Uyuni, tourism, postmodernity, ethnicity

**E-mail: damirgalaz@gmail.com 


\section{Introducción}

Cuando Neil Armstrong vio la Tierra desde el Apolo 11 no fue la Gran Muralla China lo que [apreciaron] sus ojos, fue el Salar de Uyuni.

Una destellante mancha blanca de 12 mil km2 que el astronauta se comprometió a visitar tras su odisea espacial.

Y Armstrong llegó hasta el altiplano, a casi cuatro mil metros de altura, uno de los lugares más planos del mundo, donde, incluso, se puede observar la redondez de la Tierra, con un escenario interminable, donde la vista confunde el cielo con el suelo.

La Tercera de Chile, 14 de agosto de 2010

Desde finales del siglo xIx, la ciudad de Uyuni $\left(66^{\circ} 15^{\prime}\right.$ a $67^{\circ} 15^{\prime}$ de longitud oeste y $19^{\circ} 20^{\prime}$ a $21^{\circ} 00^{\prime}$ de latitud sur), enclavada en el altiplano de Bolivia, experimentó lógicas de concentración y enclave económico, a través de actividades mineras, mecánicas, ferroviarias y de comercio (Bobillier, 1897; Bellessort, 2002-2003 [1897]; Arce, 1930; Chungara, s. f.; Mesa Gisbert, De Mesa y Gisbert, 2007; Ahumada, 1999; López, 2009).

Desarticulada la maestranza ferroviaria por el proceso de privatizaciones llevado a cabo por el gobierno de Gonzalo Sánchez de Lozada (1993-1997), y disminuidas la frecuencia y la relevancia de los ferrocarriles, Uyuni quedó sin su mayor fuente laboral, lo que desencadenó una dislocación que atraviesa desde el trabajo hasta las imágenes de representación de una ciudad ferroviaria (López, 2009). El Estado modificó el curso económico de la ciudad y provocó una desestructuración social y, sobre todo, demográfica (Chungara, s. f.; Mesa Gisbert, De Mesa y Gisbert, 2007; López, 2009), que se ha reflejado en una alta emigración y diseminación de uyunenses entre la región de Atacama y la costa chilena (López, 2009) y en otras ciudades de Bolivia y del norte argentino. ${ }^{1}$

No obstante, a partir del segundo lustro de la década de 1990, el poblado se ha ido posicionando en el concierto económico regional como el portal de ingreso al destino turístico Desiertos blancos y lagunas de colores, publicitado por empresas privadas y por el Estado boliviano, lo cual ha redundado en la llegada masiva de agencias de servicios turísticos y de transporte.

${ }^{1}$ Entrevista a Alberto André Guamán, exalcalde de Uyuni, comerciante, residente de Uyuni, febrero de 2013. 
El apogeo turístico tiene que ver irremediablemente con la posesión del salar más grande del mundo, que genera una atracción internacional de gran significado para la economía boliviana. Uyuni se transforma en el punto de partida o de finalización de una infinidad de circuitos turísticos que a diario recorren la periferia del gran salar y que abarcan islas, montañas, pueblos, salares espejos y lagunas.

En la crisis evidenciada, el ocaso de la ciudad ya desertificada y la configuración de una nueva lectura hacia el medio natural forjaron una reinscripción y reconversión de la ciudad. En un contexto de visualidad posmoderna, el turismo ha generado un polo de atracción masivo, convirtiéndose en su principal sostén. Salares, poblados altiplánicos, lagunas y cementerios de trenes reconvirtieron las dinámicas internas que, junto con una mayúscula población flotante, han intervenido el curso de la economía y las relaciones sociales y fronterizas (Chungara, s. f.; Mesa Gisbert, De Mesa y Gisbert, 2007; López, 2009, 2011).

\section{Población flotante: turistas}

Según el censo poblacional realizado en 2011, Uyuni posee una población de 18705 habitantes, que en el transcurso de los años se ha visto superada sustancialmente por la población flotante.

De acuerdo con los registros obtenidos en el municipio de Uyuni, en la Reserva Nacional de Fauna Andina Eduardo Avaroa (que colinda con el salar de Uyuni) el flujo turístico tiene un crecimiento constante de $4.5 \%$ (datos de la Dirección Municipal de Turismo y Cultura de Uyuni, febrero de 2013).

Como se expresa en el cuadro 1, las cifras pasan de 25436 turistas en el año 2000 a casi 79000 en el 2010, esto significa que se triplican. Con excepción del leve descenso en el último año, los visitantes han ido en constante aumento. Por lo visto, las cifras son inmunes a una serie de procesos económicos críticos en Europa y Latinoamérica.

Los países de los cuales proviene la mayoría de visitantes de Uyuni son, en orden de importancia, los siguientes: Francia (15\%), Inglaterra (14.40\%), Alemania (8.9\%), Israel (8\%) y, en menores proporciones, Suiza, Holanda, Australia, Estados Unidos, Italia y España (datos de la Dirección Municipal de Turismo y Cultura de Uyuni y de la Oficina de Información Turística con sede en Uyuni, febrero de 2013). Los turistas europeos cubren casi 70 \% del total de visitantes. 
Cuadro 1. Detalle del flujo turístico (número de turistas) en el área, 2000-2010

\begin{tabular}{lrrrrrrrrrrrr}
\multicolumn{1}{c}{ Mes } & \multicolumn{1}{c}{ AÑos } \\
& 2000 & 2001 & 2002 & 2003 & 2004 & 2005 & 2006 & 2007 & 2008 & 2009 & 2010 \\
\hline Enero & 2051 & 1780 & 3151 & 3391 & 3215 & 4086 & 5163 & 5834 & 6772 & 7825 & 8410 \\
Febrero & 1372 & 857 & 2123 & 2417 & 2687 & 2913 & 3449 & 4156 & 5332 & 5414 & 6213 \\
Marzo & 2246 & 2049 & 3452 & 3019 & 3302 & 4062 & 4699 & 5396 & 6624 & 6375 & 6213 \\
Abril & 2075 & 2511 & 1354 & 3923 & 4560 & 4803 & 5634 & 6130 & 6309 & 7477 & 6841 \\
Mayo & 2091 & 2050 & 3164 & 3999 & 4001 & 4558 & 4700 & 5814 & 6200 & 6500 & 5915 \\
Junio & 1445 & 1782 & 2209 & 3009 & 2936 & 2402 & 3803 & 4285 & 4563 & 4931 & 4952 \\
Julio & 2910 & 3669 & 2670 & 5471 & 4895 & 5014 & 6421 & 7436 & 8912 & 8828 & 8411 \\
Agosto & 3580 & 4212 & 5483 & 6580 & 5836 & 6539 & 6771 & 7523 & 8502 & 8477 & 6671 \\
Septiembre & 1734 & 2890 & 3628 & 3918 & 3661 & 3669 & 4269 & 4687 & 4893 & 5334 & 5636 \\
Octubre & 1446 & 2671 & 3592 & 3004 & 3671 & 4626 & 4737 & 5489 & 4692 & 6520 & 6517 \\
Noviembre & 2468 & 3317 & 3978 & 3550 & 4512 & 4930 & 5046 & 5855 & 6370 & 7360 & 6908 \\
Diciembre & 2018 & 3112 & 3124 & 3313 & 3727 & 3669 & 4462 & 4970 & 5339 & 6182 & 5799 \\
TOTAL & 25436 & 30900 & 37928 & 45594 & 47003 & 51271 & 59154 & 67575 & 74508 & 81223 & 78486 \\
\hline
\end{tabular}

Fuente: Datos de la Dirección Municipal de Turismo y Cultura de Uyuni (febrero de 2013).

A nivel latinoamericano sobresalen, en el primer lugar, Brasil; después, Bolivia y, a continuación, Argentina (datos de la Dirección Municipal de Turismo y Cultura de Uyuni, febrero de 2013). Según esta fuente, los turistas que más visitan la reserva Eduardo Avaroa y el salar de Uyuni son jóvenes, con rangos de edad que van de los 20 a los 35 años.

Por lo general, los turistas "buscan el disfrute y [la] contemplación escénica, a través del contacto con la naturaleza y la fauna. Un porcentaje importante de la demanda, especialmente en época alta, valora el ambiente natural y es medioambientalmente consciente y responsable" (datos de la Dirección Municipal de Turismo y Cultura de Uyuni, febrero de 2013). En el mismo sentido, el diario La Razón ha indicado: "Bolivia recibió un millón de turistas extranjeros en 2012 [...] El principal destino visitado el año pasado fue el Salar de Uyuni, el fondo de un antiguo mar disecado de 10000 kilómetros cuadrados que posee la mayor reserva mundial de litio, seguido de cerca por el lago Titicaca”.

2 "Bolivia recibió un millón de turistas extranjeros en 2012", La Razón Digital, 3 de enero de 2013 $<$ http://www.la-razon.com/sociedad/Bolivia-recibio-millon-turistas-extranjeros_0_1754224637.html > . 
Cuadro 2. Detalle del flujo turístico hotelero, 2012 (número de turistas)

\begin{tabular}{lccc} 
Mes & NaCiOnales & ExtRAnJERos & Total \\
Enero & 2219 & 5373 & 7592 \\
Febrero & 1494 & 5122 & 6616 \\
Marzo & 1967 & 4341 & 6308 \\
Abril & 2351 & 3834 & 6185 \\
Mayo & 1809 & 3172 & 4981 \\
Junio & 1404 & 2532 & 3936 \\
Julio & 1770 & 3372 & 5142 \\
Agosto & 2319 & 3090 & 5409 \\
Septiembre & 2369 & 2123 & 4492 \\
Octubre & 2607 & 4013 & 6620 \\
Noviembre & 2504 & 3950 & 6454 \\
Totales & 22813 & 40922 & 63735 \\
\hline
\end{tabular}

Fuente: Datos de la Dirección Municipal de Turismo y Cultura de Uyuni (febrero de 2013).

\section{¿Qué visitan?}

En nuestro trabajo de campo realizado en la ciudad de Uyuni y sus zonas contiguas pudimos corroborar que todos los días la ciudad es invadida por miles de extranjeros con rumbo al gran salar y a la numerosa cantidad de atractivos diseminados en sus bordes. Cientos de cámaras fotográficas se preparan para obtener los efectos ópticos que genera la gran alfombra blanca de sal. Mientras tanto, en las ferias y almacenes que colindan con la plaza de la ciudad, se venden postales y libros sobre los efectos ópticos y los contrastes cromáticos del medio natural uyunense. Revistas y letreros que afirman que "En Uyuni es posible caminar en el cielo", "En Uyuni tendrás el cielo a tus pies" son solo escasos ejemplos de la gran cantidad de aforismos que se esparcen por el poblado altiplánico, que a su vez son reforzados por el posicionamiento de Uyuni en los diarios internacionales, véase entre otros lo que el diario español El País ha 
publicado sobre Uyuni, sitio al que califica como el poseedor del paisaje más surrealista del planeta. ${ }^{3}$

De manera gradual, la fama de Uyuni se ha ido extendiendo por el mundo y, en ese tenor, desde octubre de 2004, el Estado la ha publicitado mediante su salar, con la imagen y propuesta publicitaria de "Desiertos blancos y lagunas de colores”. La promoción de la región altiplánica comprende todo el norte del departamento de Potosí y casi en su totalidad las provincias Daniel Campos, Nor Lípez y Sud Lípez, donde se encuentra la Reserva Nacional de Fauna Andina Eduardo Avaroa. En Uyuni se inician todos los trayectos centrados en esa nueva lectura y revalorización del medio; las agencias turísticas buscan satisfacer a sus clientes $\mathrm{y}$, constituidos como imanes turísticos, han seleccionado los sitios descritos en el cuadro 3, los cuales pudimos visitar durante nuestra etnografía turística.

Estos atractivos turísticos se distinguen por la inserción de tramas y relatos que pasan por lo geológico, lo geográfico, lo botánico, lo rupestre, lo arqueológico, lo antropológico y, en algunos casos, lo histórico, pero todo dentro de un marco que destaca la belleza del altiplano: lo místico, lo exótico, lo prístino y lo único.

Nielsen, Calcina y Quispe (2003) consideran que el turismo se ha desarrollado como un fenómeno "espontáneo", sin planificación alguna y como resultado de iniciativas privadas aisladas y exógenas:

[El turismo] no ha sido elegido por la población local, la que tampoco ha tenido oportunidad de intervenir en su diseño, desarrollo o administración. Los beneficios económicos de esta industria recaen en su mayor parte sobre las empresas de turismo de Uyuni y otros centros urbanos de Bolivia y Chile. Tal como está organizada actualmente la actividad, la única participación económica de la población se da a través del servicio de alojamiento que, como se señaló oportunamente, está concentrado en un número reducido de vecinos de tres o cuatro localidades [...] Más compartidos están los perjuicios que ocasiona el turismo a las comunidades originarias y a su patrimonio. El interés que muestran los visitantes por el pasado local ha llevado a una depredación sistemática del patrimonio arqueológico [Nielsen, Calcina y Quispe, 2003: 372].

3 “Los paisajes más surrealistas del planeta”, El País, 22 de noviembre de 2012 < http://elviajero.elpais. com/elviajero/2012/11/21/actualidad/1353501157_451286.html >. 


\section{Cuadro 3. Sitios turísticos de Uyuni}

\begin{tabular}{|c|c|}
\hline Sitios & Datos \\
\hline Cementerio de trenes & $\begin{array}{l}\text { Ubicado a tres kilómetros de la ciudad de Uyuni, consta de } \\
\text { una veintena de locomotoras a vapor, vagones y carros. Es la } \\
\text { desmantelación de la maestranza depositada en el altiplano. }\end{array}$ \\
\hline Salar de Uyuni & $\begin{array}{l}\text { Posee una extensión de más de } 12000 \mathrm{~km}^{2} \text {, se encuentra a } 3653 \\
\text { msnm y es uno de los más extensos del mundo; posee alrededor } \\
\text { de } 32 \text { islas con ecosistemas singulares, cactus gigantes, vizcachas y } \\
\text { ocasionalmente picaflores. Está rodeado por montañas volcánicas entre } \\
\text { las cuales sobresale el cerro Thunupa, con una altura de } 5432 \mathrm{msnm} \text {. }\end{array}$ \\
\hline Colchani & $\begin{array}{l}\text { Población situada a } 20 \mathrm{~km} \text { de Uyuni, considerada una de las más } \\
\text { importantes debido a su centro de extracción y procesamiento de sal, } \\
\text { con una capacidad de producción de casi } 20000 \text { ton al año, de las } \\
\text { cuales } 90 \% \text { se destina al consumo humano. También destaca por sus } \\
\text { ferias artesanales donde la sal es la materia prima. }\end{array}$ \\
\hline Isla Incahuasi & $\begin{array}{l}\text { Ubicada en el centro del salar, a } 164 \mathrm{~km} \text { de Uyuni, está constituida por } \\
\text { una colina cubierta de cactus de hasta } 12 \mathrm{~m} \text { de altura con diámetros } \\
\text { de } 50 \mathrm{~cm} \text {. Es muy cotizada por sus paisajes e ilusiones ópticas que la } \\
\text { convierten en un lugar muy fotografiado. }\end{array}$ \\
\hline San Juan de Rosario & $\begin{array}{l}\text { Se encuentra en la ruta troncal Colcha K y Chiguana, al extremo sur de } \\
\text { la isla de Lliphi, a } 3660 \mathrm{~m} \text { de altitud. Sus habitantes viven del cultivo } \\
\text { de la quinua real sin utilizar químicos. Posee casas con varios albergues } \\
\text { turísticos y fue uno de los primeros sitios de la región en involucrarse } \\
\text { en la actividad turística. }\end{array}$ \\
\hline $\begin{array}{l}\text { Necrópolis de los } \\
\text { señoríos Lípez }\end{array}$ & $\begin{array}{l}\text { Conjunto de tumbas preincaicas ( } 1250 \text { al } 1532 \text { d. C.) con apariencia } \\
\text { de colmenas, distribuidas en cuatro hectáreas. Las tumbas fueron } \\
\text { descubiertas a partir del amontonamiento de rocas blandas de toba } \\
\text { volcánica, que fueron excavadas para depositar momias en su interior. } \\
\text { Se halla a } 300 \text { m de la comunidad. }\end{array}$ \\
\hline Museo Kausaywasi & $\begin{array}{l}\text { Ubicado en San Juan de Rosario, cuenta con cerca de } 300 \text { piezas } \\
\text { arqueológicas clasificadas según normas nacionales de la Dirección } \\
\text { Nacional de Arqueología. }\end{array}$ \\
\hline Santiago de Chuvica & $\begin{array}{l}\text { Poblado ubicado a } 12 \mathrm{~km} \text { de Colcha K, sobre el camino a San Juan de } \\
\text { Rosario, Avaroa (frontera con Chile). El sustento económico de sus } \\
\text { habitantes es la quinua real y la papa nativa, cultivadas en la planicie y } \\
\text { en las laderas del cerro, actividades que han sido patrimonializadas en } \\
\text { torno al turismo. }\end{array}$ \\
\hline Lacaya & $\begin{array}{l}\text { Ruinas altamente visitadas; el lugar es considerado uno de los } \\
\text { asentamientos precolombinos más importantes de la región de Lípez y } \\
\text { objeto de importantes estudios arqueológicos. Abarca siete hectáreas } \\
\text { distribuidas en dos grandes sectores: un reducto fortificado en lo alto } \\
\text { de una colina y un poblado a sus pies, que data de los siglos XII a XVII } \\
\text { d. C. Los objetos encontrados en este lugar corresponden a diferentes } \\
\text { épocas, desde preincaicas hasta la novohispana. }\end{array}$ \\
\hline
\end{tabular}




\section{Cuadro 3. Sitios turísticos de Uyuni (continuación)}

\begin{tabular}{|c|c|}
\hline Sitios & Datos \\
\hline Santiago de Agencha & $\begin{array}{l}\text { Ubicado al suroeste del salar, aquí también se cultiva la quinua real. } \\
\text { Posee miradores en colinas para contemplar las puestas de sol. }\end{array}$ \\
\hline Gruta de la Galaxia & $\begin{array}{l}\text { Situada a } 7 \mathrm{~km} \text { de la localidad de Aguaquiza, al norte de la isla Lli’phi } \\
\text { y al sur del salar. Es una caverna subacuática formada por erupciones } \\
\text { volcánicas sobre las aguas del lago Minchin (hoy salar) en la etapa } \\
\text { previa a las glaciaciones. Presenta una conformación muy diferente de } \\
\text { las rutas terrestres porque, en lugar de las acostumbradas estalactitas y } \\
\text { estalagmitas, desde el techo se proyectan cuerpos calcáreos con formas } \\
\text { de solidificación del magma al contacto con el agua. }\end{array}$ \\
\hline Cueva del Diablo & $\begin{array}{l}\text { Se ubica en la misma colina de la gruta de la Galaxia, a escasos metros } \\
\text { de esta caverna; en su interior tiene construcciones precolombinas. } \\
\text { Desde sus miradores pueden verse el salar y las serranías circundantes. }\end{array}$ \\
\hline Llavica & $\begin{array}{l}\text { Comunidad próxima a Aguaquiza, donde existen cultivos de quinua } \\
\text { real en los cerros, cultivos prácticamente puros, con tecnologías } \\
\text { agrícolas ancestrales. }\end{array}$ \\
\hline San Pedro de Quemes & $\begin{array}{l}\text { Municipio que posee variados sitios de interés turístico, como el volcán } \\
\text { Irupuntuku, Cana, las aguas termales de Empexa y el pueblo quemado. }\end{array}$ \\
\hline Tahua & $\begin{array}{l}\text { Poblado sumamente concurrido por turistas. Sus habitantes hablan se } \\
\text { manera predominante en aymará. Se halla a } 123 \mathrm{~km} \text { de la ciudad de } \\
\text { Uyuni en dirección noreste. }\end{array}$ \\
\hline Ayquepucara & $\begin{array}{l}\text { Localidad ubicada al pie del cerro Thunupa; es un sitio arqueológico } \\
\text { enclavado en uno de los brazos más australes. Conforma una colina a } \\
265 \text { msnm, con una superficie de aproximadamente } 5 \text { ha; lugar muy } \\
\text { importante por la presencia arqueológica de vestigios aymaras de } \\
\text { alrededor del año } 1300 \text {. }\end{array}$ \\
\hline Coqueza Chantani & $\begin{array}{l}\text { Población localizada a } 8 \mathrm{~km} \text { de Tahua, tiene un mirador y un } \\
\text { observatorio astronómico en una colina del cerro Thunupa, a } 4132 \\
\text { msnm. En una caverna que se encuentra en las laderas de Thunupa } \\
\text { se exhiben momias de señoríos aymaras del Intercalar, que datan de } \\
\text { aproximadamente el año } 1250 \text { d. C. Se está montando el museo Palacio } \\
\text { de los cántaros y áreas marinas petrificadas con figuras humanas y } \\
\text { animales. }\end{array}$ \\
\hline San Agustín & $\begin{array}{l}\text { Poblado que posee paisajes formados por la actividad volcánica, con } \\
\text { mesetas de hasta } 4500 \text { msnm y serranías, así como "amorfos" tallados } \\
\text { sobre rocas basálticas. En el cerro San Gerónimo se halla también el } \\
\text { santuario de los cóndores. }\end{array}$ \\
\hline Mallku Villamar & $\begin{array}{l}\text { Su nombre original es Mallku Cueva, por la cueva donde se reunían } \\
\text { los mallkus. En la comunidad se realizan ferias con diversos productos } \\
\text { artesanales en piedra y tejidos. }\end{array}$ \\
\hline Tomas Laqa & $\begin{array}{l}\text { Conjunto de formaciones rocosas peculiares y desgastadas por fuerzas } \\
\text { eólicas. Posee pinturas rupestres de las épocas preincaica e incaica, } \\
\text { que presentan figuras antropomorfas, zoomorfas, ornitomorfas } \\
\text { y geométricas. Además se encuentran petroglifos delicadamente } \\
\text { terminados con figuras de serpientes y zorros. }\end{array}$ \\
\hline
\end{tabular}




\section{Cuadro 3. Sitios turísticos de Uyuni (continuación)}

\begin{tabular}{|c|c|}
\hline Sitios & Datos \\
\hline Puka Pukara & $\begin{array}{l}\text { Es una fortaleza preinca que posee bodegas de reserva de alimentos. } \\
\text { Se conservan muros defensivos con paredes altas y pequeñas ventanas } \\
\text { para observar a los grupos hostiles. También se hallan piedras en forma } \\
\text { de bola que se usaban como proyectiles. Las construcciones de la parte } \\
\text { alta servían como refugio para los guardianes, desde donde podían } \\
\text { vigilar su territorio. }\end{array}$ \\
\hline Llajtaqaqa & $\begin{array}{l}\text { Es un roquedal formado por espuma volcánica petrificada y tallada } \\
\text { por el viento, que ostenta atractivas formas para el turismo, que libran } \\
\text { una apariencia de cuidado; de ahí su nombre en quechua, que significa } \\
\text { Ciudad de Piedra. Es promovido por ser un lugar "ideal” para observar } \\
\text { vizcachas y águilas. }\end{array}$ \\
\hline Desierto Siloli & $\begin{array}{l}\text { En él se encuentra el conocido Árbol de Piedra. Está ubicado a } 18 \mathrm{~km} \\
\text { al norte de la Laguna Colorada. Se caracteriza por sus formas rocosas } \\
\text { originadas de la espuma de flujos de lava petrificada erosionada por el } \\
\text { viento. }\end{array}$ \\
\hline Laguna Colorada & $\begin{array}{l}\text { Se localiza a una altura de } 4278 \mathrm{msnm} \text {; es la más grande de la } \\
\text { región, con una extensión de } 60 \mathrm{~km} \text { y una profundidad de } 80 \mathrm{~cm} \text {. Es } \\
\text { considerada el sitio más importante para observar flamencos; posee } \\
\text { un singular color rojizo brillante, debilitados pigmentos de algas } \\
\text { microscópicas y sedimentos que cambian de intensidad a lo largo del } \\
\text { día. La rodean salares, volcanes nevados y aguas termales. }\end{array}$ \\
\hline Sol de Mañana & $\begin{array}{l}\text { Ubicado a } 50 \mathrm{~km} \text { al sur de la Laguna Colorada, es el sector más alto } \\
\text { de la región con una altura que bordea los } 5000 \mathrm{msnm} \text {. Se distingue } \\
\text { por sus cráteres, que generan una constante actividad volcánica; se } \\
\text { observan lava, fumarolas que desprenden gases de azufre y pozos que } \\
\text { por lo general producen emisiones verticales de vapor de agua de } 10 \text { a } \\
50 \mathrm{~m} \text { de altura y, excepcionalmente, de } 80 \text { hasta casi } 200 \mathrm{~m} \text { de altura. }\end{array}$ \\
\hline Salar de Chalviri & $\begin{array}{l}\text { Se encuentra en la parte central de la reserva Eduardo Avaroa. Posee } \\
\text { una superficie de } 1000 \mathrm{~km} \text { y en su centro se halla una empresa minera } \\
\text { basada en la explotación de bórax, aditivos de fertilizantes, esmaltes y } \\
\text { vidrios. }\end{array}$ \\
\hline $\begin{array}{l}\text { Aguas termales de } \\
\text { Polques }\end{array}$ & $\begin{array}{l}\text { Al oeste de Chalviri está la enorme Laguna Salada o Polques, con } \\
\text { pequeñas piscinas calientes que alcanzan una temperatura de } 28 \text { a } 30 \\
\text { grados, a las cuales se les atribuyen cualidades curativas o medicinales, } \\
\text { en especial para enfermedades como la artritis y el reumatismo. }\end{array}$ \\
\hline $\begin{array}{l}\text { Pampa Jara (Rocas } \\
\text { Dali) }\end{array}$ & $\begin{array}{l}\text { Se localiza a } 5000 \mathrm{msnm} \text {; en este lugar pueden apreciarse enormes } \\
\text { formaciones de rocas. }\end{array}$ \\
\hline Laguna Verde & $\begin{array}{l}\text { Es una laguna de agua salada ubicada en la Reserva Nacional de Fauna } \\
\text { Andina Eduardo Avaroa. Presenta una coloración verde esmeralda } \\
\text { debido a su alto contenido de magnesio, carbonato de calcio, plomo } \\
\text { y arsénico. "En esta laguna no existe ningún tipo de vida porque es } \\
\text { tóxica", señalan las agencias de turismo. }\end{array}$ \\
\hline
\end{tabular}




\section{Cuadro 3. Sitios turísticos de Uyuni (finaliza)}

\begin{tabular}{|c|c|}
\hline Sitios & DAtos \\
\hline Volcán Licancabur & $\begin{array}{l}\text { Se localiza en la Cordillera Occidental a } 5960 \text { msnm. En su cima hay } \\
\text { una depresión a modo de cráter cubierta de agua del mismo tono de } \\
\text { la Laguna Verde. El lugar se presta para practicar el montañismo. Las } \\
\text { características geológicas, biológicas, mesotérmicas y medioambientales } \\
\text { del volcán tienen supuestamente una "similitud con las del planeta } \\
\text { Marte." }\end{array}$ \\
\hline San Pablo de Lípez & $\begin{array}{l}\text { Se halla en los pies del cerro San Pablo y en las riberas del río de igual } \\
\text { nombre; es una localidad circundada por las lomas Capitán y Cóndor } \\
\text { Wasi, su nombre proviene de la creencia de que en el lugar apareció } \\
\text { la imagen de san Pablo apóstol. Posteriormente, cuando fue declarada } \\
\text { capital de la provincia, se le añadió la palabra Lípez. }\end{array}$ \\
\hline San Cristóbal & $\begin{array}{l}\text { Histórica comunidad minera situada al suroeste de Uyuni, cercana a } \\
\text { la que será una de las minas a tajo abierto más grandes del mundo. } \\
\text { El asentamiento Pueblo Nuevo, actual San Cristóbal, está a } 12 \mathrm{~km} \text { del } \\
\text { pueblo antiguo, el cual se terminó de construir en junio de } 1999 \text {. En el } \\
\text { antiguo pueblo se encuentran los yacimientos de mineral (plata, plomo } \\
\text { y zinc), que serán explotados por la Minera San Cristóbal. }\end{array}$ \\
\hline
\end{tabular}

Fuente: Elaboración propia.

El apogeo turístico de Uyuni ha implicado la llegada de docenas de agencias foráneas, muchas de las cuales operan desde el extranjero. ${ }^{4}$ No obstante, podemos listar las que en el año 2012 se encontraban registradas en el centro comercial de la ciudad:

- Andes Salt Expeditions

- Andes Travel Office

- Andrea Tours

- Avi Tours

- Blue Line Service

- Brisa Tours

${ }^{4}$ Entrevista a Santos Mamani, operador turístico y profesor universitario, residente de Uyuni, febrero de 2013. 
- Collahuasi S.R.L.

- Colque Tours

- Cordillera Tours

- Copacabana Travel

- Culpina “K” Tours

- Dayan Tours

- Diamante Tours

- Esmeralda Tours

- Euro Tours

- Expediciones Castilla

- Expediciones Discovery

- Expediciones Empexsa

- Expediciones Gaviota

- Expediciones Incahuasi

- Expediciones Lípez

- Expediciones Monte Blanco

- Expediciones Nueva Ventura

- Expediciones Sajama

- Fely Tours

- Fremen Tour Andes \& Amazonía

- Huaynuma Tours

- Isla Tours

- Jhaneth Tours

- Joyas del Sur

- Joya del Sur de Bolivia

- Juliet Tours

- Kantuta Tours

- Laqaya Tours

- Natours and Salt Field Trips

- Oasis Odyssey Tours

- Olivos Tours
- Perla de Bolivia Tours

- Pamela Tours

- Pukara Tours

- Relámpago Tours

- Reli Tours

- Sajama Traveller

- Sajama Turismo Licancabur

- Salar Paula Tours

- San Juan Tours

- Sandra Travels

- Sumaj Jallpha Tours

- Toñito Tours

- Trans Andino Tours

- Sol de Mañana Tours

- Tunupa Tours

- Turisbaal Expediciones

- Turismo Amanecer

- Turismo Cordillera Traveller

- Turismo El Cristal

- Turismo El Desierto

- Turismo Jhovana

- Turismo Kory Wasy

- Turismo Ollagüe

- Turismo Playa Blanca

- Turismo Sucre

- Turismo Tierra Hermosa

- Uyuni Eagles

- Uyuni Tours

- Vieli Expediciones

- Wara del Altiplano

- Zamar Tours 
Este listado omite a agencias que no están inscritas o formalizadas en los registros municipales, sino que operan de modo particular con contactos realizados por familiares en otras ciudades de Bolivia o sin autorización municipal. ${ }^{5}$ Otras agencias están ubicadas en San Pedro de Atacama y extienden sus servicios de modo transfronterizo. Sin embargo, todas son muestra de una actividad que refleja masividad y un proceso inmigratorio translocal y transfronterizo.

\section{Visualidad posmoderna}

Este escenario de turismo masivo lleva a preguntarnos sobre las ventajas comparativas de Uyuni, sobre los elementos que destacan en este escenario de paisajes en altura, desiertos altiplánicos y grandes extensiones del salar, que es el mayor desierto de sal continuo del mundo, con una superficie de 12000 $\mathrm{km}^{2}$. En qué medida estos paisajes, situados a $3650 \mathrm{msnm}$ (en algunos casos a $5000 \mathrm{~m}$ ), son llamativos para lejanos viajeros, 0 ¿cómo se acomoda la ciudad de Uyuni al poseer el salar con una de las mayores reservas de litio en el mundo, con importantes cantidades de potasio, boro y magnesio? (Cypher y Dietz, 2004).

Desde la escala cronológica humana, estos paisajes siempre han estado allí, y las manifestaciones culturales pueden ser rastreadas arqueológica e históricamente, si bien sabemos que el turismo ha significado una reconversión laboral de la ciudad. No obstante, cabe preguntarnos qué hecho o proceso ha llevado a releer el medio para mercantilizarlo. 0 , qué tipo de proceso operó para generar un gran flujo de turistas extranjeros que han llegado masivamente a Uyuni en los últimos 20 años; qué ocurre en los países de Europa, Asia o Norteamérica para que sus ciudadanos decidan visitar paisajes considerados exóticos y únicos; por qué se "descubren" estos paisajes hace solo dos décadas; qué pasaba antes; qué pasará después; por qué surge el turismo y sus infinitas variantes en los estertores del siglo xx; en qué medida la visualidad y la estetización del medio determinan estos procesos de capitalización turística en Uyuni.

Nuestras respuestas remiten irremediablemente a un fenómeno visual y de estetización, tal como habíamos adelantado. Pero, ipor qué lo visual hegemoniza las búsquedas del turismo? Lo visual se conecta con procesos que remiten

${ }^{5}$ Entrevista a Santos Mamani, operador turístico y profesor universitario, residente de Uyuni, febrero de 2013. 


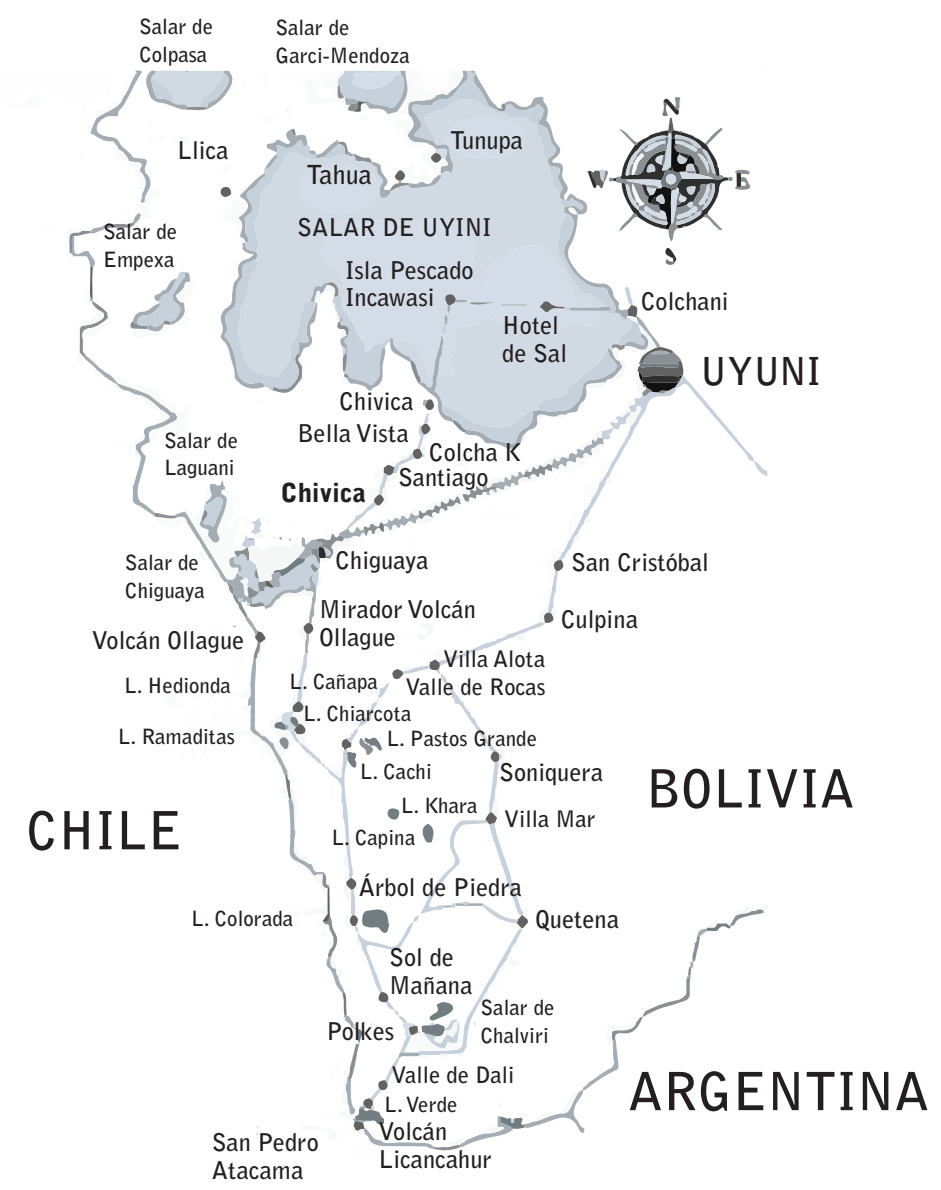

Fuente: Elaboración propia.

Figura 1. Mapa turístico de la reserva ecológica Avaroa y los circuitos de la ciudad de Uyuni 
a una renovación de ideologías y de relativismos filosóficos que han llevado a formar un nuevo escenario que podemos vincular con la posmodernidad, y en el cual, una vez considerados caídos los regímenes de metarrelatos o discursos maestros (algunos pensadores equiparan esta "caída" con la de los socialismos duros de Europa, es decir, la caída del muro de Berlín y el fin de la Guerra Fría), pasamos de una cultura de la razón a una cultura de la sospecha (Estermann, 2009: 30): "lo único que nos queda es la contemplación estética de la realidad mediante los parámetros estéticos consumistas, en una dualidad de lo bello y lo no bello" (Estermann, 2009: 31). Consumo hedonista clave en una economía neoliberal (Moulian, 1998) en donde se conecta el turismo sudamericano.

En otras palabras, esta actitud filosófica y comercial es la superación de la "razón ilustrada", que buscaba totalizar al mundo en sus concepciones (Lyotard, 1979). En estas lógicas predominó la ciencia positivista, el cientificismo, el idealismo y el historicismo (Estermann, 2009: 29). Los portadores de estos metarrelatos se apropian de un supuesto orden racional del cosmos, del mundo y del devenir de sus habitantes. Sin embargo, la concepción de posmodernidad no es más que una nueva expresión de Occidente, quizá pudiese considerarse una rama más del postestructuralismo. Entonces, la posmodernidad no significa una superación de la "filosofía de Occidente", sino una deconstrucción de los relatos para elaborar otras "verdades” (Lyotard, 1979; Estermann, 2009).

Uyuni y su público visualista (resultado de la corriente posmoderna) son quizá la expresión de una nueva generación hedonista de la parte rica de la tierra (que históricamente remite a cierta burguesía colonizadora). La indiferencia propagada por la posmodernidad como una nueva liberación ante las metanarrativas solo puede permitírsela quien tiene satisfechas las necesidades básicas. Para viajar y turistear, el hedonista debe tener resueltas sus necesidades terrenales, para conectarse así con los grupos de poder económico o con parte de "las pequeñas o grandes burguesías". Parafraseando a Estermann, podríamos preguntarnos si acaso el turista es quien no tiene hambre.

En el caso de Uyuni, el turismo no es más que la manifestación de un grupo múltiple de extranjeros con mirada ávida de belleza, tranquilidad, colores y exotismo ${ }^{6}$, aunque belleza como construcción que opera con cánones europeos.

${ }^{6}$ Entrevista a Santos Mamani, operador turístico y profesor universitario, residente de Uyuni, febrero de 2013. 
"El esteticismo postmoderno enfatiza la conversión de valores cognoscitivos, éticos y sociales en valores netamente estéticos, de agrado o desagrado. Lo más diverso y lo menos homogéneo y monótono, el fenómeno, lo más bello y agradable” (Estermann, 2009: 30). Nielsen, Calcina y Quispe agregan que el proceso iniciado en Uyuni se relaciona con una especie de cultura "híbrida" y globalizada, que entre otras cosas se traduce en el auge de nuevas formas de turismo: turismo cultural, científico, místico, receptivo, rural, vivencial, ecoturismo, turismo de aventura, etc. Diversas facetas de un interés creciente entre los sectores con mayores recursos, sobre todo de los países centrales, por acceder a experiencias directas de un mundo natural y cultural diverso y "prístino" (Nielsen, Calcina y Quispe, 2003), que parece desvanecerse ante el avance del desarrollo económico, del occidentalismo, del neocapitalismo, del consumo y de la digitalización de la realidad actual.

Desde estos enfoques se evidencia una superación de "la verdad" hegemónica que nos relacionaba con el nosotros y con los otros; solo quedaría la contemplación como acción redentora para dar paso a una estetización de la realidad. Entonces, axiológicamente no debería haber diferencias basadas en valores éticos (Lyotard, 1983). Frente a esto, Estermann afirma que en la contemplación de la realidad, del medio y del mundo predominan los caracteres estéticos consumistas: se puede seguir hablando de diferencias culturales, socioeconómicas, religiosas y físicas, pero ya no hay manera de valorar estas diferencias en términos de marginación, explotaciones, presiones o injusticia. La verdad solo se da en plural, los valores éticos se transforman en estéticos (Estermann, 2009). En este cambio de paradigma es relevante destacar cómo, en un escenario de consumo, los medios de comunicación y sus visualidades descritas remiten a este proceso de estetización que se difunde de forma ininterrumpida.

Así, la posmodernidad llevaría ligada en su acontecer un axioma de lo visual. El ver se cruza con el captar, con el cerciorar, para comprender la realidad; asimismo, se cruza con lo "objetivo", con lo cierto, con lo vivido y lo palpable, y tiene relación con el aprehender, con una actitud activa frente a un supuesto pasivo, como una cacería intelectual del recolector de imágenes. El paisaje, el medio y la sociedad se estancan, se esencializan en un proceso de autenticación consumista por parte de los recaudadores de imágenes. Usualmente se busca 162 lo estancado, lo que remite al pasado, a lo genuino, a lo que se detuvo, para 
experimentar una catarsis y una tranquilidad frente al escenario neoliberal que nos individualiza. Lo nativo es una forma supuesta de naturalidad y armonía con el medio. Estermann afirma que "el mundo se convierte entonces en un espectáculo gigantesco de donde unos pocos [...] disfrutan del estreno lucha por la supervivencia” (2009: 32). Lo nativo, entonces, remite a una involución supuesta según la lógica posmoderna, que pasa de lo ético a lo estético.

Si hablamos de la superación de verdades absolutas y dogmáticas, en este entorno de deconstrucción gnoseológica isurge la vivencia de un escenario de muchas verdades, de una pluralidad que es incomparable y cuyas cosmovisiones, relatos, organizaciones, políticas, sociedades y materialidades podemos captar solo a través de la contemplación? Se dejan de lado las reducciones semánticas, teóricas y valóricas. "Bajo ninguna condición, el metarrelato racionalista occidental puede ser el criterio último de racionalidad y verdad, ni juez ético y axiológico de los demás discursos vigentes en distintas épocas y culturas" (Estermann, 2009: 34). Sucumbe la supuesta universalidad del conocimiento etnocéntrico de Occidente.

\section{“Autenticidades" y estéticas}

Al sostener la hegemonía de una búsqueda estética como resultado de una era posmoderna y como superación de la ética resultante del mundo moderno, vemos que el turismo en Uyuni se relaciona con la búsqueda de autenticidades, en aras de una razón artesanal.

En los alrededores de la plaza uyunense es posible hallar una serie de pizzerías y restaurantes de comida extranjera (estadounidense, japonesa y china) y una gran cantidad de comercios de artesanías, muchas de ellas con motivos aymaras y quechuas. Los turistas circulan todo el día por estas ferias adquiriendo gorros, guantes, pulseras, polleras, chalecos, ponchos, etc. Se configura un pequeño mundo que manifiesta una relación confusa entre feria y museo, entre el comercio y los elementos de carácter etnográfico. (Podríamos preguntarnos entonces, ¿una feria puede ser un museo? ¿la diferencia entre museo y feria radica en que se puede comprar lo observado?)

A escasos tres kilómetros de la ciudad de Uyuni se encuentra el cementerio de ferrocarriles, con decenas de locomotoras, vagones y carrocerías de todo tipo que yacen en pleno desierto, oxidados y abandonados por las empresas 
ferroviarias que acumularon aquellos fierros que hoy constituyen el interés turístico de miles de personas. En nuestro trabajo de campo pudimos comprobar que el cementerio de ferrocarriles es visita obligada de todos los circuitos turísticos de Uyuni.

Este cementerio es la fiel expresión del final de una vida industrial de decenas de ferrocarriles, de una maestranza desmantelada. Con todo, en cuanto cementerio es la manifestación de una vitalidad, entendida como expresión de la vigencia que adquieren estas máquinas muertas, pero a la vez como museo, en un escenario post mortem. La vitalidad que surge en la muerte genera una musealización y una patrimonialización. No obstante, podemos afirmar que la fuerza estética de este museo no intencionado o no planificado radica en una fuerza estética etnográfica basada en una poética de la muerte, la cual cruza el cementerio y la exposición comercial de artesanías. En consecuencia, estos objetos son mirados desde la simbología de la desaparición: el objeto adquiere valor porque ha desaparecido, está desapareciendo o desaparecerá aquel que lo utilizaba. Sobre la crítica de cierta razón artesanal, Richard (2006) indica que los objetos contienen ya y en sí mismos esa desaparición. Objeto y extinción. Esa desaparición -acontecida o por acontecer- es su condición de representación y de su valor. El museo administra esa relación. De ahí proviene el carácter aurático de ese objeto: en el silencio sacrosanto del museo, ese objeto que no se transa, que es casi un cadáver, la delegación de un cadáver, escena muda, un cadáver por procuración (Richard, 2006).

Desde este punto de vista, las artesanías indican el desuso de un hábito, de una costumbre o de una cotidianidad: "Ese objeto es como el que se usaba pero que ya no se usa. Es copia, símil, reproducción. Ni aura ni cadáver: si el objeto etnográfico sindica la extinción del cuerpo, el objeto artesanal señala el abandono de un uso, la retracción de una cultura, el desempleo de un instrumento" (Richard, 2006: 821).

En aquel sentido, todo aquello revela una economía de la representación de algo "auténtico", de lo "original", de lo "exótico", de lo que se va perdiendo y se desea rescatar al comprarlo, o bien visitando el cementerio de ferrocarriles para fotografiarlo y subirse a esos vagones muertos, para fotografiar el aura que le da el paso del tiempo.

164 La búsqueda de la artesanía por parte del turista alude a la búsqueda de la autenticidad. Se impone así un discurso foráneo sobre el local, y lo local busca 
inscribirse dentro de ese discurso hegemónico que persigue una realidad étnica. Se construye entonces una etnicidad con meros fines comerciales, se elabora un esencialismo que considera a la cultura como estática, ajena a todo proceso dinámico.

En la primera década del siglo xxi, Uyuni consolida su vocación turística por encima de lo agropecuario, lo minero y, principalmente, lo ferroviario. Se trata de una reconversión con base en los nuevos paradigmas que se fueron desencadenando en la sociología de los países desarrollados, que han coadyuvado a releer el medio en un proceso de patrimonialización que incluye una mercantilización integral de los sitios que han despertado el interés de los alóctonos. Por su parte, la población local de Uyuni se centra en satisfacer los requerimientos de los turistas: alojamientos, restaurantes, locomoción, entre otros, con lo que genera una especie de burbuja turística en el centro comercial de la ciudad, en especial en la plaza y en la estación de ferrocarriles, lo cual produce un verdadero gueto turístico, tal como ocurre en el centro de Cusco (Stell, 2006).

De este modo, Uyuni construye una etnicidad, una supuesta "esencia" propia, a saber: que es una ciudad relativamente nueva (fue fundada en 1889). No obstante, el proceso de etnogénesis orienta una inscripción en el mundo quechua y aymara, en la cual cooperan los vendedores de artesanías, que en su mayoría son foráneos, igual que las decenas de agencias turísticas que ayudan a reinterpretar el medio para explicarlo y venderlo a un turista ansioso de "autenticidad", de "acercamiento con la naturaleza”, consumidor posmoderno de una visualidad paisajística.

Lo que acontece en Uyuni se vincula también con un redescubrimiento de la alteridad americana, cuyos antecedentes se remontan a los tiempos de la dominación española, y que deriva en la construcción del "indio", del colonizado (el en ocasiones declarado subhumano). A ese subhumano, en la terminología colonial, había que colonizarlo, evangelizarlo, para que fuera como "nosotros", todo en términos de alienación, de dominación y muchas veces de aniquilación. Había una negación del otro; negándolo como indio se incorporaba, dentro de sus "limitaciones", al "nosotros", a "Occidente".

Empero, la negación, la incorporación y la exclusión tienen formas más “civilizadas” en la actualidad, operan nuevamente las lógicas y los procederes coloniales, que radican en "declarar el propio pensamiento como etnofilosofía, construir filosofías anatópicas en culturas no occidentales, [se busca] occidentalizar a 
la elite no-occidental, musealizar [...] y estetizar formas autóctonas de concebir el mundo" (Estermann, 2009: 27).

En un juego neocolonial, se ha cambiado la espada y la cruz por la cámara fotográfica y la chaqueta The North Face, el caballo colonial por el Jeep, la búsqueda del oro por la fotografía y el efecto óptico del salar de Uyuni. Este turismo altera y modifica la cotidianidad del uyunense, quien construye y renueva su vida para satisfacer al foráneo en una neocolonización solapada. Si el espejo era cambiado por oro en tiempos de la Conquista española, ahora las agencias turísticas administran el efecto tipo espejo (el reflejo del cielo en las aguas del inmenso salar) como una verdadera mina de oro.

\section{Hagiografía ferroviaria}

En estas innovaciones conceptuales de lo que Uyuni comprende sobre su propio devenir histórico vemos también una producción hagiográfica como representación de una ciudad que giró en torno a un ferrocarril. Una vez que este ha decaído, notamos que esta tendencia agrega otro proceso martirológico a los ferroviarios. Una construcción de relato centrado en la mitificación, donde se cruza la muerte con la gloria de la cual el turismo se satisface.

Por esta construcción hermenéutica del pasado, emergen los numerosos monumentos que consignan y recrean la imagen del ferroviario. Las esculturas de una épica surgen en una especie de santidad urbana, y se multiplican las fotografías del pasado puestas en las vitrinas, en los libros, en los salones, en los grafitis.

Se evidencia sin duda una dimensión de inconsciencia subliminal, referida a cómo surge una función cuyo objetivo es instrumentar la subjetividad y el universo simbólico para construir una identidad corporativa de la ciudad. Así, en las calles de Uyuni se pueden ver imágenes y recuerdos de cierta sacralidad corporativa que proyecta un universo simbólico, con la autoexaltación de una labor ya extinta.

En ese sentido, las biografías, las materialidades y los relatos históricos se transforman en una narración con tintes de "sagrado", como un símbolo de vida personal y comunal a través del significado peculiar de sus labores y del 166 mito que subyace a ella en cuanto a relatos, anécdotas laborales, historias paranormales y cierto "destino" de gloria, configurador de un "pasado glorioso", 
quizá como necesidad social de una contingencia histórica y que, por procesos políticos nacionales, emergió como una genealogía de la desaparición.

Tal vez el relato mítico intenta representar una dislocación de sentidos: esas formas no condicionadas por la historia son insuficientes, innecesarias y aun distorsionadas para explicar el origen, la función y el desarrollo instrumental y técnico de las instituciones con que son conectadas, con una labor que se constituye como el motor de la historia de la ciudad.

La visión de hierofanía expresada en el relato ferroviario hace que la estación, la maestranza y las propias locomotoras sean casi un lugar sagrado e iniciático, que luego será musealizado. Los uniformes y las herramientas de los ferroviarios se establecen como elementos atávicos para la conformación de una identidad local.

En los abandonados talleres el indígena se reconvirtió, su etnicidad fue el molde en donde se vaciaron los saberes mecánicos que formaron al ferroviario.

En la figura 2 se observan algunos ejemplos de una representación ferrocéntrica: una ferretería, la indicación de una avenida, una estatua (proceso de patrimonialización) y un cine ferroviario (monumentalización), que sugieren una tendencia a cierta hagiografía laboral, imágenes que se reproducen, se valoran y se legitiman desde la memoria en una ciudad turística.
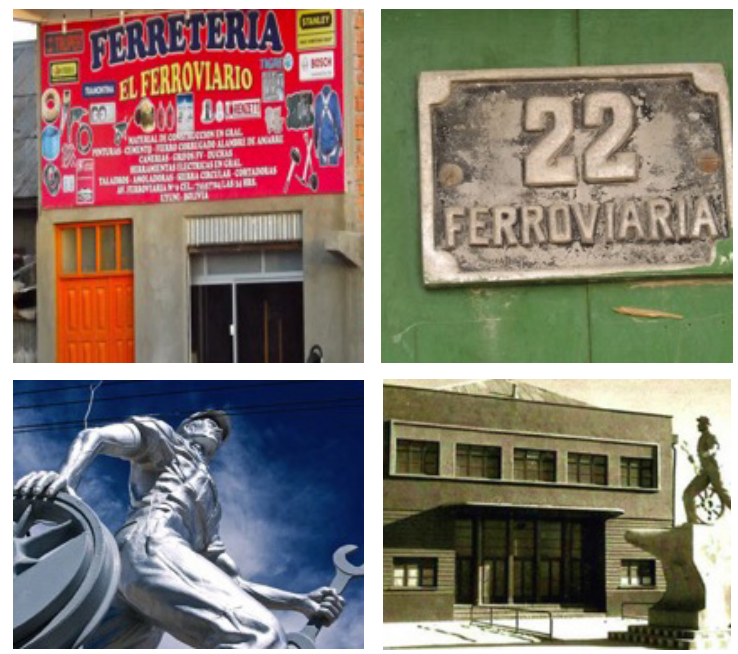

Figura 2. Representación ferrocéntrica 
Las maquinarias dispuestas en la avenida Ferroviaria de Uyuni (hoy patrimonizalizadas) contribuyen a las representaciones de la vida ferroviaria. La historia es entendida y expresada desde estas materialidades y tecnologías como un fetiche acumulativo; cada cosa tiene un valor por exponer un momento de la “evolución” de la ciudad. El vestigio museográfico de Uyuni es quizá un problema político, generado por ver al pueblo como en vías de desaparición, como supervivencia de la modernidad. Es un valor de exotismo. Acaso iel proceso de patrimonialización en Uyuni tiene que ver con dar una valor, un precio, a una singularidad, a lo que no tiene precio? (véase figura 3).

Finiquitadas las labores en la Empresa Nacional de Ferrocarriles del Estado (ENFE), la cesantía derivó también en una irónica reconversión vinculada con la patrimonialización de las labores en sí mismas. El trabajo extinto y el jubilado
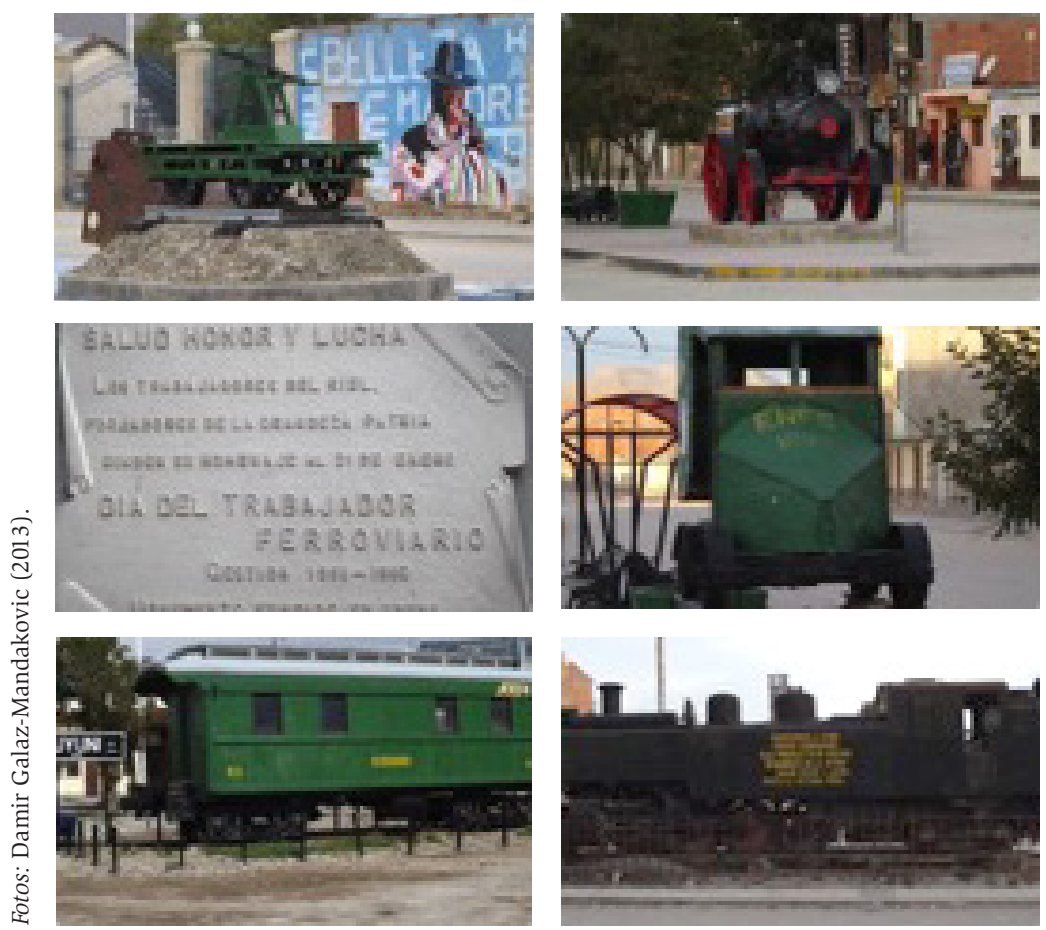

Figura 3. Maquinaria en la avenida Ferroviaria de Uyuni 

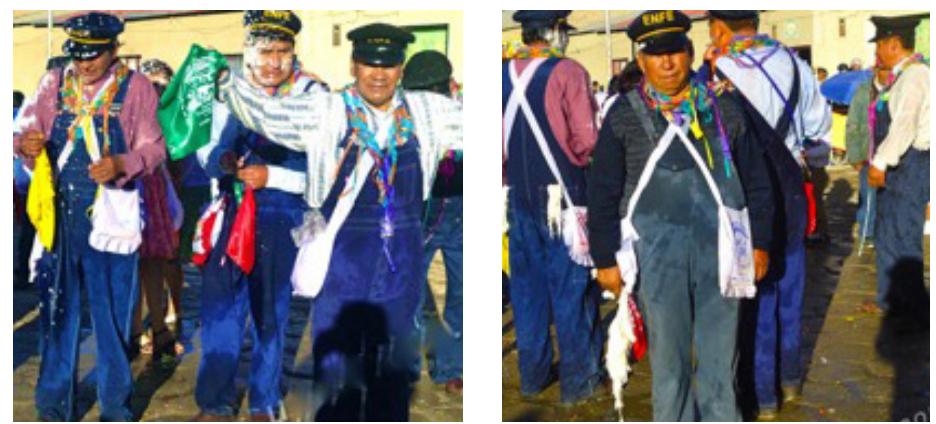

Fotos: Damir Galaz-Mandakovic (2013).

Figura 4.

o cesante se valorizan desde y para el turismo; se exhiben como "baluarte de la historia”, "cuna del sindicalismo boliviano", "lucha laboral”, categorías basadas en los imaginarios de la ciudad y su proyección en Bolivia.

\section{Comentarios finales}

La posesión del salar más grande del mundo, además de una serie de pueblos, lagunas, rocas, cementerios, volcanes, miradores, entre otros sitios, ha generado una fuerte atracción y una fama mundial que han sido claves para el sostén de la economía boliviana en la puna subandina. De este modo, se ha generado una dependencia económica directa respecto del flujo de visitantes. Por ello, gran parte de la población dirige sus actividades hacia la atención de estas demandas.

El cuadro 4 refleja las principales actividades desarrolladas en la ciudad. Desde el punto de vista cuantitativo son más relevantes el comercio y los servicios, lo que da muestra del peso del turismo como agencia económica. En tercer lugar se posiciona la construcción, que atestigua un proceso de expansión urbana fruto del turismo, que ha generado la llegada de población foránea y las edificaciones destinadas a la atención de los visitantes: hoteles, hostales, casas de acogida, restaurantes, entre otras. La actividad minera se encuentra entre las últimas posiciones, situación que marca un contraste con la tónica fundacional de la ciudad.

El turismo constituye una reconversión económica casi absoluta en Uyuni; se 
Cuadro 4. Características generales de la ocupación en Uyuni

\begin{tabular}{|lc|}
\hline \multicolumn{1}{|c}{ ACTIVIDAD } & NÚMERO DE PERSONAS \\
\hline Agricultura & 215 \\
Pesca & 0 \\
Explotación de minas & 55 \\
Producción manufacturera & 302 \\
Producción de energía eléctrica & 12 \\
Construcción & 173 \\
Comercio & 799 \\
\hline Servicios & 1630 \\
\hline
\end{tabular}

Fuente: Municipalidad de Uyuni, con base en datos del censo de 2001 y de 2005 a 2010.

trata de una conexión con los procesos sociológicos y antropológicos derivados de una economía neoliberal que facilita el consumo, además de la búsqueda de la belleza prístina desde el eurocentrismo, de donde surge una idea de las culturas del altiplano desde un esencialismo cultural, que da paso a la consideración de una cultura como objeto fijo y acabado del cual solo quedan "rasgos". Esto no implica las miradas que entienden la cultura como efecto procesualista; no existen los espacios para los cambios. El turista favorece la uniformidad de la cultura en la herencia y los discursos centrados en la diversidad cultural. El turismo en Uyuni y los alrededores del salar niega los espacios para comprender la cultura a partir de los procesos, los dinamismos, la creación, por lo que se estaría negando al sujeto. La pregunta es si acaso los vecinos de Uyuni son moldeados por estos enfoques al autopresentarse como pueblos tradicionales, como patrimonios vivientes con manifestaciones culturales en "peligro de extinción”.

El turismo, entendido como el desplazamiento temporal para descansar y adquirir nuevas experiencias cruza recreo, ocio y aprendizaje. En ese sentido, el turismo de masas, en cuanto expresión de globalización y estrategia local de desarrollo, lo justifica como una nueva forma de relación étnica entre culturas "vivas” y “muertas”. En esa relación surgen también dudas sobre el territorio, por 170 saber que los inversionistas en Uyuni hacen que el dinero salga de la región: se importan los materiales y alimentos, incluso muchos viajes también son paga- 
dos en el extranjero. Los uyunenses se preguntan ¿de quién es la ciudad?

Para concluir, consideramos que el turismo en Uyuni se constituye desde una trama discursiva de mercantilización de estéticas exóticas comprendidas con base en un enfoque eurocéntrico que luego es asumido por los propios bolivianos. Este turismo de masas se explica también por una Europa neoliberal con cierta noción del vacío existencial por efecto de su modelo económico; agréguese la disminución de la religión, el aumento del nihilismo y del relativismo, así como el desarrollo del individualismo. Estos procesos llevan a buscar nuevos significados, a imaginar nuevas realidades, a representar cosmos étnicos que son comercializados por las agencias en cuanto procesos culturales escasos y extintos.

En Uyuni, la mercantilización modifica las costumbres de las comunidades, que se sitúan en un escenario de mercado y de teatro ante innumerables actos performativos para mostrar al turista los modos de vida supuestamente originarios.

Las comunidades, junto con el guía posmoderno eurocéntrico y esencialista americano, construyen sus remontándose a ficciones, artificios, mundos místi-

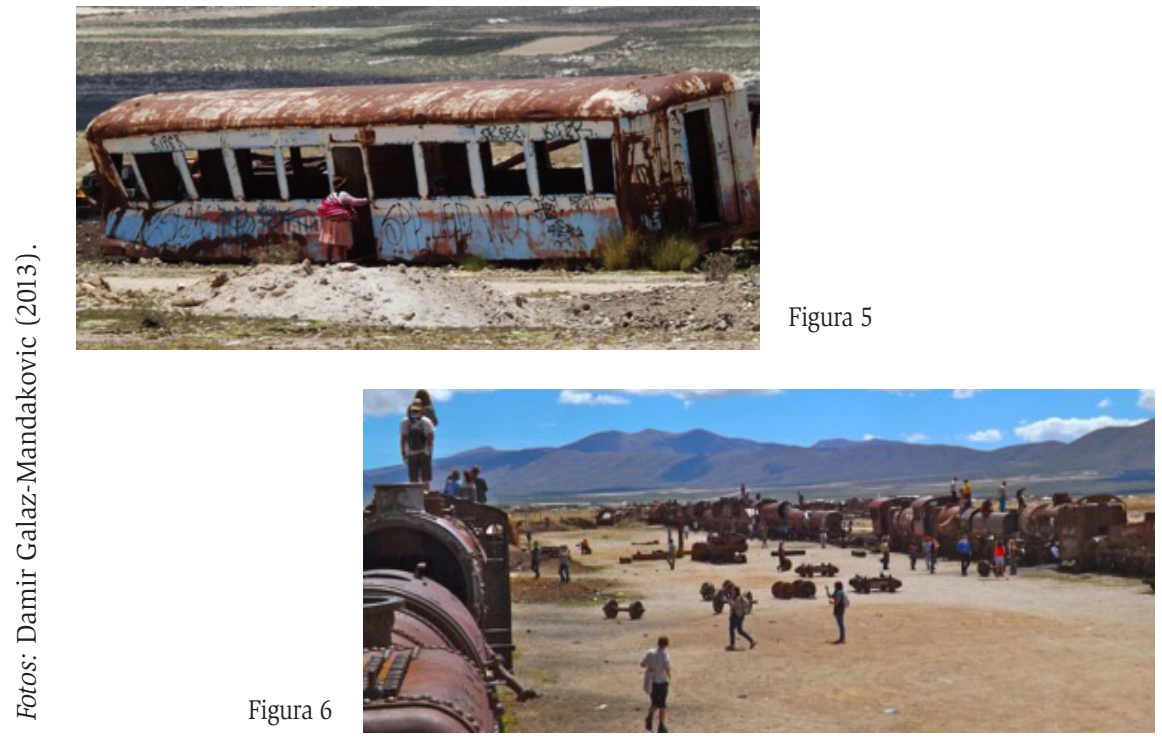

Figura 5 y 6. La expresión de dos realidades paralelas: Pobreza frente a turismo cultural. 
cos, exóticos y glorificadores del pasado: el escenario es la posmodernidad, la visualidad, la exoticidad de un turismo que desborda el devenir de una ciudad.

Las figuras 5 y 6 nos ofrecen la oportunidad de una última reflexión. El saqueo de "bienes turísticos" o de desperdicios mecánicos que han sido depositados en el altiplano (a $3 \mathrm{~km}$ de Uyuni) constituye la paradoja de una dualidad: por un lado, las antiguas locomotoras y los vagones componen un interés turístico, de una "belleza turisteable" y fotografiable, mecánicas que se transforman en "patrimonio material” usufructuado por las agencias (figura 6) que día a día brindan a centenas de turistas la posibilidad de llegar a fotografiar las abandonadas locomotoras y los vagones. Por otro lado, vista la pobreza, la precariedad de la ciudad, la desigual distribución de la riqueza y la falta de oportunidades para el mundo indígena, estos archivos de la mecánica se convierten en verdaderas piezas de ayuda ante apuros económicos (figura 5). Latas, pedazos de aluminio, cobre, acero y otras piezas son extraídas y comercializadas o son destinadas a la confección de cocinas, mesas, chimeneas, hornos, etc. Es la expresión de dos realidades paralelas: el turismo cultural en despilfarro y los desconectados con el turismo, transportadores, en algunas ocasiones, del hambre.

\section{Fuentes CONSULTADAS}

Ahumada, M.T. (1999). Huanchaca: El establecimiento industrial de Playa Blanca en Antofagasta. Antofagasta: Universidad José Santos Ossa.

Arce, I. (1930). Narraciones históricas de Antofagasta. Antofagasta: Imprenta Moderna.

Bellessort, A. (2002-2003) [1897]. Joven América: Chile y Bolivia [en línea]. Trad. de Hernán Minder. Disponible en: http://www.memoriachilena. cl/602/articles-122641_recurso_5.pdf

Bobillier, E. (1897). “La Compañía Huanchaca de Bolivia”. Anales del Instituto de Ingenieros, XII (81), 15 de octubre, 167-230.

Chungara, V. (s. f.). Tradiciones y leyendas de Uyuni. Uyuni: Autoedición.

Cypher, J. y J. Dietz (2004). The Process of Economic Development. Londres: 
Estermann, J. (2009). Filosofía andina. 2a ed. La Paz: Abya-Yala .

López, V. (2009). Uyuni: Historia de un pasado glorioso. Cochabamba: Adonai. - (2011). Antología de la ciudad más desventurada de Bolivia. Respuestas fundamentales de hechos que forjaron la identidad y personalidad de Uyuni. Potosí: Adonai.

Lyotard, J-F. (1979). La condition postmoderne: Rapport sur le savoir. París: Les Éditions de Minuit. (1983). Le Différend. París: Les Éditions de Minuit.

Mesa Gisbert, C.D., J. de Mesa y T. Gisbert (2007). Historia de Bolivia. La Paz: Gisbert.

Moulian, T. (1998). El consumo me consume. Santiago de Chile: Lom Ediciones. Nielsen, A., J. Calcina y B. Quispe (2003). "Arqueología, turismo y comunidades originarias: una experiencia en Nor Lípez (Potosí, Bolivia)”. Chungará. Revista de Antropología Chilena, 35 (2), 369-377.

Richard, N. (2006). "Cinco muertes para una breve crítica de la razón artesanal”. Anales de Desclasificación [en línea], 1 (2), 810-825. Disponible en: http://www.academia.edu/8442358/critica_de_la_razon_artesanal

Steel, G. (2006). "Turismo y vendedores ambulantes en Cuzco", en A. Ypeij y A. Zoomers (eds.), La ruta andina: Turismo y desarrollo sostenible en Perú y Bolivia. Quito/Cuzco/Ámsterdam/Lima: Abya-Yala/Centro Bartolomé de Las Casas/Centro de Estudios y Documentación Latinoamericana/Instituto de Estudios Peruanos, 169-186. 